\title{
Use of pharmacist blood pressure telemonitoring systems in diagnosis of nocturnal hypertension in a young healthy male
}

This article was published in the following Dove Press journal:

Patient Preference and Adherence

I September 2014

Number of times this article has been viewed

\author{
Tomohiro Mizuno',* \\ Chizuru Matsumoto $1, *$ \\ Nobuko Nabetani ${ }^{2}$ \\ Yoshinari Yasuda ${ }^{3}$ \\ Tadashi Nagamatsu' \\ Norimasa Umemura ${ }^{2}$ \\ 'Department of Analytical \\ Pharmacology, Faculty of Pharmacy, \\ Meijo University, Nagoya, Japan; \\ ${ }^{2}$ Haruka Community Pharmacy, \\ Nagoya, Japan; ${ }^{3}$ Department of \\ Chronic Kidney Disease Initiatives, \\ Nagoya University Graduate School \\ of Medicine, Nagoya, Japan \\ *These authors contributed equally \\ to this work
}

Correspondence: Tomohiro Mizuno Department of Analytical Pharmacology, Faculty of Pharmacy, Meijo University, I50 Yagotoyama, Tempaku, Nagoya 468-8503, Japan

Email mizunot@meijo-u.ac.jp

\begin{abstract}
Blood pressure (BP) telemonitoring systems and pharmacist management programs were introduced into Haruka Community Pharmacy. A 22-year-old healthy male came to the community pharmacy, although he was not in a diseased state, he had been informed previously that he had a moderately high BP during a routine examination. He continued home BP telemonitoring for 28 days. A pharmacist intervention was conducted at 2 week intervals. His average nighttime systolic BP was higher than the daytime systolic BP. The pharmacist consulted a doctor based on the BP telemonitoring results, and ambulatory blood pressure monitoring (ABPM) was initiated. The doctor detected nocturnal hypertension based on the results of ABPM monitoring. BP telemonitoring systems have been introduced into a small percentage of pharmacies in Japan, and this is the first case report for the usefulness of these systems in a community pharmacy.

Keywords: community pharmacy, management, ambulatory blood pressure monitoring
\end{abstract}

\section{Introduction}

"Out-of-office" blood pressure (BP) monitoring is important in the diagnosis and management of hypertension. ${ }^{1}$ Out-of-office BP is commonly assessed by ambulatory BP monitoring (ABPM), or home BP monitoring (HBPM) which involves selfmeasurement. Previous reports suggest that HBPM is readily accepted and conducted by hypertensive patients. ${ }^{2-4} \mathrm{An}$ increasing number of hypertensive patients are using the technique to check HBPM regularly, whereas young healthy subjects seldom check their BP. The rate of HBPM is very low in young healthy people, thus many cases of hypertension have been ignored.

New communication technologies have been introduced in order to facilitate routine BP measurements. In particular, home BP telemonitoring systems can lead to better BP control compared to the traditionally used methods..$^{5-7}$ Margolis et al suggested that home BP telemonitoring systems and pharmacist case management can result in better BP control compared to usual care ${ }^{8}$ However, only a few pharmacies currently use BP telemonitoring systems in Japan.

Pharmacist management programs using BP telemonitoring systems were recently introduced into our community pharmacy (Haruka Community Pharmacy, Nagoya, Japan). This system is based on physician-pharmacist comanagement, and we present a case of a young healthy male who was diagnosed with nocturnal hypertension.

\section{Case presentation}

A 22-year-old healthy male came to Haruka Community Pharmacy. Although he was not in a diseased state, he was found to have a moderately high BP during a medical 


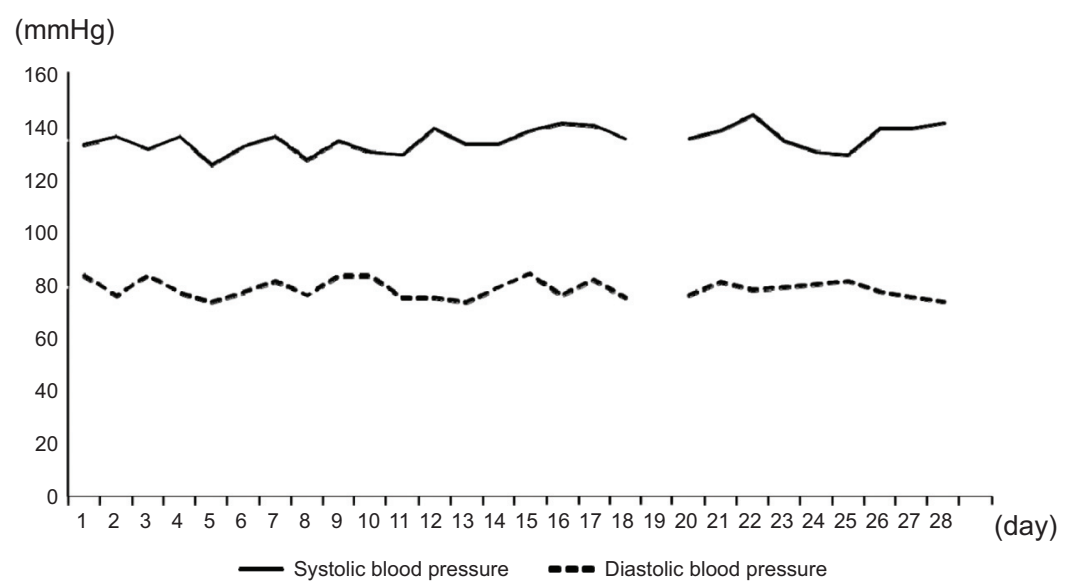

Figure I Average of systolic and diastolic blood pressure values.

Notes: Blood pressure (BP) values are presented as the mean per day. Systolic BP is shown as a solid line. Diastolic BP is shown as a dashed line. The BP was not measured on day 19.

examination at his university. He was not a shift worker, and had normal sleeping patterns. The community pharmacist recommended that he check his HBPM regularly, and hence, he began HBPM. The home BP telemonitoring system involved the use of Medical LINK (Omron Healthcare Co., Ltd., Muko, Kyoto, Japan). This system wirelessly transmits BP data to a central web server via a mobile network. The community pharmacist can examine the patient's BP data at any time via the Internet.

The pharmacist advised the patient to measure his BP twice per day (when he wakes up and before he goes to bed), and gave him a printed handout outlining the importance of lifestyle modification before starting BP monitoring. A pharmacist intervention was conducted every two weeks during the monitoring period. Briefly, the pharmacist collected information regarding his lifestyle from an interview, and advised him about lifestyle modification. Home BP telemonitoring was continued for a period of 28 days.

The average values of the patient's systolic and diastolic BPs are shown in Figure 1. Although the frequency of measuring his BP at home was $85.7 \%$ before the monitoring period (data not shown), it was increased to $96.4 \%$ afterward (Figure 1). The mean values for daytime and nighttime systolic blood pressures were $131 \mathrm{mmHg}$ and $137 \mathrm{mmHg}$, respectively, and diastolic blood pressure was $78 \mathrm{mmHg}$. Therefore, the patient did not have daytime hypertension, as shown by the telemonitoring measurements. The average nighttime systolic BP was higher than that of the daytime BP (Figure 2). The pharmacist consulted a physician based on the results of $\mathrm{BP}$ telemonitoring, and $\mathrm{ABPM}$ was conducted. BP was measured for a 24-hour period using an FB-270 device
(Fukuda Denshi Co., Ltd., Tokyo, Japan). The BP values during ABPM are shown in Figure 3. "Nighttime" was defined as the patient's actual sleeping time, based on his diary. The mean daytime and nighttime $\mathrm{BP}$ were 135/80 $\mathrm{mmHg}$ and $120 / 73 \mathrm{mmHg}$, respectively. We defined hypertension as a BP of 135/85 mmHg or higher for daytime BP and 120/70 $\mathrm{mmHg}$ or higher for nighttime BP based on the Japanese Hypertension guidelines. ${ }^{9}$ Thus it was concluded that the patient had nocturnal hypertension.

\section{Discussion}

In the present case report, the pharmacist advised a young healthy male to be on HBPM, and he successfully performed the monitoring at regular intervals. Moreover, the

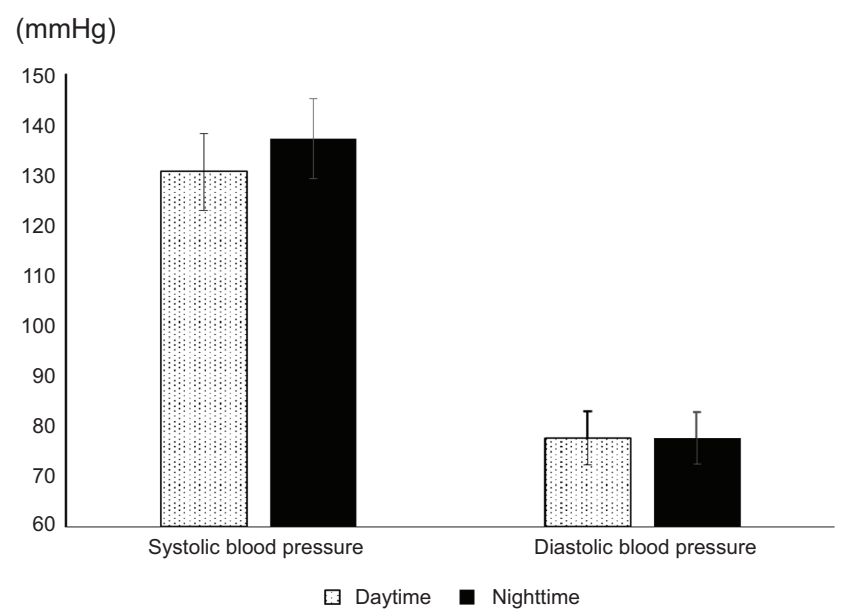

Figure 2 Comparison of average daytime and nighttime blood pressure during the monitoring periods.

Notes: Blood pressure (BP) values are presented as the mean \pm standard deviation. The mean values for daytime and nighttime systolic $\mathrm{BP}$ were $131 \mathrm{mmHg}$ and $137 \mathrm{mmHg}$, respectively, and diastolic BP was $78 \mathrm{mmHg}$. 


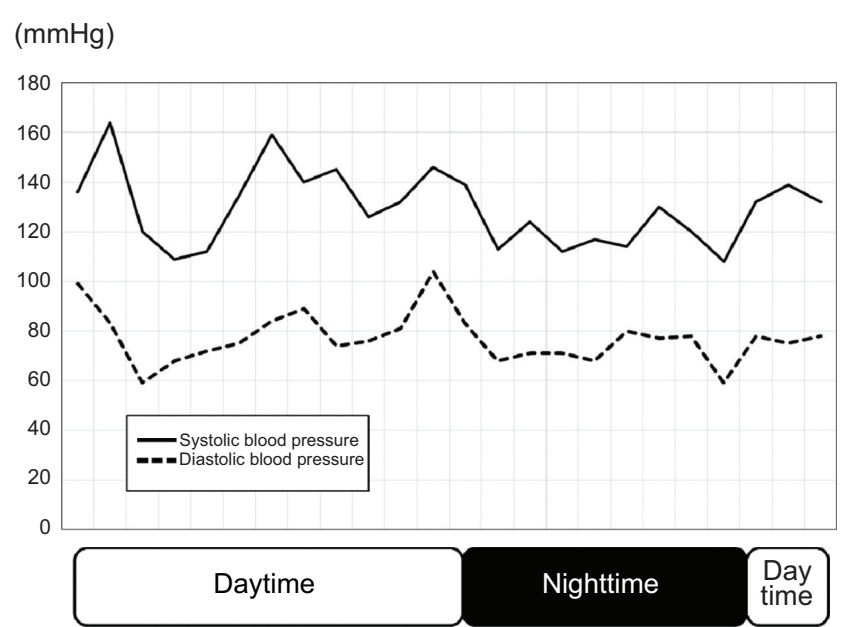

Figure 3 Blood pressure (BP) during ambulatory blood pressure monitoring periods.

Notes: Nighttime was defined as the actual sleep time based on the patient's diary. The mean daytime or nighttime BPs were $135 / 80 \mathrm{mmHg}$ and $120 / 73 \mathrm{mmHg}$, respectively.

pharmacist consulted with a physician based on the results of BP telemonitoring, and the patient was diagnosed with nocturnal hypertension.

Some young healthy males have elevated brachial systolic $\mathrm{BP}(\geq 135 \mathrm{mmHg})$ and normal values of brachial diastolic BP ( $\geq 85 \mathrm{mmHg}$ ) but there is no evidence to show that they benefit from antihypertensive treatment. ${ }^{1}$ Previous reports suggested that the physician-pharmacist comanagement of hypertension can be useful for controlling BP..$^{10,11}$ In the present case, pharmacist management programs using a BP telemonitoring system improved patient adherence in terms of measuring his BP. BP telemonitoring systems have been introduced into a small percentage of pharmacies in Japan, and this is the first successful case report of the use of such a system in a community pharmacy. Although further studies in patients with hypertension will be needed, these programs in which telemonitoring systems are used might be useful for collaborative drug therapy management in community pharmacies.

\section{Disclosure}

The authors declare no conflicts of interest in this work.

\section{References}

1. Mancia G, Fagard R, Narkiewicz K, et al. 2013 ESH/ESC guidelines for the management of arterial hypertension: the Task Force for the Management of Arterial Hypertension of the European Society of Hypertension (ESH) and of the European Society of Cardiology (ESC). Eur Heart J. 2013;34(28):2159-2219.

2. Parati G, Stergiou GS, Asmar R, et al. European Society of Hypertension guidelines for blood pressure monitoring at home: a summary report of the Second International Consensus Conference on Home Blood Pressure Monitoring. J Hypertens. 2008;26(8):1505-1526.

3. Pickering TG, Miller NH, Ogedegbe G, Krakoff LR, Artinian NT, Goff D. Call to action on use and reimbursement for home blood pressure monitoring: a joint scientific statement from the American Heart Association, American Society Of Hypertension, and Preventive Cardiovascular Nurses Association. Hypertension. 2008;52(1):10-29.

4. Parati G, Stergiou GS, Asmar R, et al. European Society of Hypertension practice guidelines for home blood pressure monitoring. $J$ Hum Hypertens. 2010;24(12):779-785.

5. McManus RJ, Mant J, Bray EP, et al. Telemonitoring and selfmanagement in the control of hypertension (TASMINH2): a randomised controlled trial. Lancet. 17 2010;376(9736):163-172.

6. Morak J, Kumpusch H, Hayn D, Modre-Osprian R, Schreier G. Design and evaluation of a telemonitoring concept based on NFC-enabled mobile phones and sensor devices. IEEE Trans Inf Technol Biomed. 2012;16(1):17-23.

7. Parati G, Omboni S, Albini F, et al. Home blood pressure telemonitoring improves hypertension control in general practice. The TeleBPCare study. J Hypertens. 2009;27(1):198-203.

8. Margolis KL, Asche SE, Bergdall AR, et al. Effect of home blood pressure telemonitoring and pharmacist management on blood pressure control: a cluster randomized clinical trial. JAMA. 2013;310(1):46-56.

9. Ogihara T, Kikuchi K, Matsuoka H, et al. The Japanese Society of Hypertension Guidelines for the Management of Hypertension (JSH 2009). Hypertens Res. 2009;32(1):3-107.

10. Weber CA, Ernst ME, Sezate GS, Zheng S, Carter BL. Pharmacistphysician comanagement of hypertension and reduction in 24-hour ambulatory blood pressures. Arch Intern Med. 2010;170(18): 1634-1639.

11. Chen Z, Ernst ME, Ardery G, Xu Y, Carter BL. Physician-pharmacist co-management and 24-hour blood pressure control. J Clin Hypertens (Greenwich). 2013;15(5):337-343.
Patient Preference and Adherence

\section{Publish your work in this journal}

Patient Preference and Adherence is an international, peer-reviewed, open access journal that focuses on the growing importance of patient preference and adherence throughout the therapeutic continuum. Patient satisfaction, acceptability, quality of life, compliance, persistence and their role in developing new therapeutic modalities and compounds to optimize

\section{Dovepress}

clinical outcomes for existing disease states are major areas of interest for the journal. This journal has been accepted for indexing on PubMed Central. The manuscript management system is completely online and includes a very quick and fair peer-review system, which is all easy to use. Visit http://www. dovepress.com/testimonials.php to read real quotes from published authors. 